\title{
Factors Affecting Physical Growth in Children with Primary Vesicoureteral Reflux: A Single Center Experience
}

\author{
(1) Rabia Miray Kışla Ekinci1, (1) Erkin Serdaroğlu² \\ 1University of Health Sciences, Dr. Behçet Uz Children's Training and Research Hospital, Clinic of Pediatrics, İzmir, Turkey \\ 2University of Health Sciences, Dr. Behçet Uz Children's Training and Research Hospital, Clinic of Pediatric Nephrology, İzmir, Turkey
}

\begin{abstract}
Aim: Primary Vesicoureteral reflux (VUR) is defined as retrograde urine flow from the bladder to the upper urinary system due to an insufficient valvular mechanism in the ureterovesical junction. We aimed to clarify factors affecting physical growth in children with primary VUR.

Materials and Methods: The study was performed retrospectively in 260 primary VUR patients without chronic renal disease. Height and weight z-scores were calculated by anthropometric references in Turkish children and compared between patients grouped according to clinical properties.

Results: Mean age of diagnosis was $43 \pm 4$ months and mean duration of follow-up was $4.2 \pm 1.4$ years. Mean height and weight z-scores of the 260 children were $0.22 \pm 0.96$ and $-0.11 \pm 1.0$ at diagnosis; $0.14 \pm 0.97$ and $0.01 \pm 1.3$ at last visit respectively. Age at diagnosis, gender, grade, laterality and persistency of VUR had no impact on height and weight parameters. Although initial and final height z-scores were similar, we showed a higher height z-score improvement in patients with renal scarring and similarly in patients with surgery performed at least 6 months after the diagnosis. Mean final height and weight z-scores and weight z-score improvement were significantly lower in patients with urinary tract infections (UTIS) than in those without UTIs at follow-up. Further analysis concerning UTIs showed that final height z-scores were significantly lower in patients with afebrile UTIs at follow up, while it was similar between patients with and without febrile UTIs.

Conclusion: The presence of renal scarring and UTIs at follow-up may lead to growth alterations in patients with primary VUR. Therefore, physicians and parents should be aware of UTI symptoms, even in the absence of fever, in pediatric VUR, thus preventing renal scarring and alterations in growth.
\end{abstract}

Keywords: Child, growth, urinary tract infection, vesicoureteral reflux

\section{Introduction}

Vesicoureteral reflux (VUR) is a common urological abnormality with a prevalence of $1-2 \%$ of the pediatric population and defined as retrograde urine flow from the bladder to the upper urinary system due to an insufficient valvular mechanism in the ureterovesical junction (1).
Although most cases with particularly low-grade VUR resolve spontaneously, its persistence accounts for 7-17 $\%$ of end-stage renal disease $(2,3)$. Diagnosis is usually made upon investigating a urinary tract infection (UTI), antenatal hydronephrosis or sibling screening. However, flank pain, proteinuria, hypertension, enuresis and voiding dysfunction may occasionally lead to diagnosis. Voiding

\section{Address for Correspondence}

Rabia Miray Kışla Ekinci MD, University of Health Sciences, Dr. Behçet Uz Children's Training and Research Hospital, Clinic of Pediatrics, İzmir, Turkey Phone: +902324116000 E-mail: mir kisla@hotmail.com ORCID: orcid.org/0000-0001-6234-822X

Received: 13.08 .2018 Accepted: 26.10.2018

${ }^{\circ}$ Copyright 2019 by Ege University Faculty of Medicine, Department of Pediatrics and Ege Children's Foundation The Journal of Pediatric Research, published by Galenos Publishing House. 
cystourethrogram (VCUG) is the reference standard test in VUR diagnosis and follow-up (4). The aim of treatment is to prevent UTIs and renal damage $(5,6)$.

Renal damage and persistent VUR have been reported to alter physical growth in former studies, however, recent data revealed no relevance between renal damage, UTIs, VUR grade and growth (7-9). With this study, we aimed to clarify factors affecting physical growth in children with primary VUR in a larger population.

\section{Materials and Methods}

\section{Patients}

The study included 260 primary VUR patients, 155 females (59.6\%) and 105 males (40.4\%), followed up between August 2003-August 2012 at our department. Patients with chronic renal disease, malabsorption or systemic diseases were excluded from the study. Age at diagnosis, symptoms prior to diagnosis, comorbid urinary abnormalities, gender, VUR grade and laterality, renal scarring, treatment procedure, time of surgery, duration of antibiotic prophylaxis, frequency of UTI (febrile or afebrile) at follow-up, VUR persistency, resolving time of VUR and growth parameters were retrospectively recorded from the medical records of the patients. In our clinical practice, height and weight had been recorded every 6 months in patients younger than 3 years of age and annually in patients older than 3 years.

Height and weight z-scores were calculated by anthropometric references in Turkish children and mean z-scores were compared within the different groups of patients (10).

VUR was diagnosed by VCUG and graded from 1 to 5 according to the criteria of the International Reflux Study Committee (11). Grade 4 and 5 VUR were classified as highgrade VUR in our study. We defined early diagnosed VUR as VUR diagnosed in the first 3 months of life. Patients are surgically treated by an endoscopic subureteric injection of polytetrafluoroethylene (Polytef) paste or Cohen's ureteroneocystostomy when necessary. Resolution was defined as an absence of VUR in VUG three months after endoscopic surgery or 6 months after open surgery (12).

Cortical scarring was defined as a defect in the normal reniform outline on dimercaptosuccinic acid scanning. A photon deficient area was defined as a focal or diffuse area of reduced uptake of the radionuclide with preservation of the normal reniform outline (13).

UTI is described as significant bacteriuria in a urine culture test taken appropriately. Significant bacteriuria is defined as \pm standard deviation $>1.000$ colony forming unit (cfu) with suprapubic, $>10.000 \mathrm{cfu}$ with catheterization technique and $>100.000 \mathrm{cfu}$ with midstream urine analysis (14-16).

The Ethics Committee of Dr. Behçet Uz Children's Training and Research Hospital approved the study (approval number: B-10-4-ISM-4-35-65-72, date: 27/09/2012). All patients and parents gave their informed consent prior to their inclusion in the study.

\section{Statistical Analysis}

The distribution of data was evaluated with the Kolmogornov-Smirnov test. If appropriate, numeric variables were analyzed with the Student t-test and ANOVA tests. If not appropriate, numeric variables were compared by the Mann-Whitney $U$ and KruskallWallis tests. Pearson correlation analysis was performed between two numeric variables. Categorical variables were analyzed with chi-square and if possible, Fisher's exact chi-square tests. Odds ratio with 95\% confidence intervals were used to quantify the risk. Analysis was performed with the (version 16.0; SPSS) statistical significance was considered at $\mathrm{p}<0.05$.

\section{Results}

The mean age at diagnosis was $43 \pm 4$ months (range: 1 to 174 months). Twenty-nine patients (11.2\%) were diagnosed as early diagnosed VUR as defined above. Mean duration of follow-up was $4.2 \pm 1.4$ years (range: $3-9$ years). Symptoms prior to diagnosis, urinary comorbidities and disease characteristics in patients are shown in Table I.

VCUG revealed mild VUR (< grade 4) in 178 (68.5\%) and severe VUR ( $\geq$ grade 4 ) in 82 (31.5\%) patients. Mean resolution time was $22 \pm 13$ months (range: 2-82 months) in patients with spontaneous resolution. Antibiotic prophylaxis was given to 248 patients (95\%) with a mean duration of $25 \pm 1$ months. Cohen's ureteroneocystostomy was performed in 59 patients with a recovery rate of $96.6 \%$ $(n=57)$, whereas VUR resolved in $48(77.4 \%)$ of 62 patients for whom endoscopic Polytef was injected.

Mean height and weight z-scores of the 260 children were $0.22 \pm 0.96$ and $-0.11 \pm 1.0$ at diagnosis; $0.14 \pm 0.97$ and $0.01 \pm 1.3$ at their last visit respectively. Initial and last height and weight z-scores and changes during follow-up were compared in patients according to gender, age at diagnosis, the presence of renal scarring, VUR grade, VUR laterality, VUR persistency, spontaneous resolution, resolution with surgery and surgery timing at follow up. This data is shown in Table II. Although initial and final height z-scores 
were found statistically similar between patients grouped according to the presence of renal scarring and surgery timing, annual height z-score improvement was found to be higher in patients with renal scarring and similarly in patients on whom a surgery was performed at least 6 months after the diagnosis. Growth parameters among the

Table I. Clinical characteristics of patients with primary vesicoureteral reflux

\begin{tabular}{|c|c|c|c|}
\hline \multicolumn{2}{|l|}{ Parameters } & \multirow{2}{*}{$\frac{\mathbf{n}}{26}$} & \multirow{2}{*}{$\begin{array}{l}\% \\
10 \\
\end{array}$} \\
\hline \multirow{5}{*}{ VUR grade } & Grade 1 & & \\
\hline & Grade 2 & 62 & 23.8 \\
\hline & Grade 3 & 90 & 34.6 \\
\hline & Grade 4 & 47 & 18.1 \\
\hline & Grade 5 & 35 & 13.5 \\
\hline \multicolumn{2}{|l|}{ Bilateral VUR } & 123 & 47.3 \\
\hline \multicolumn{2}{|l|}{ Renal scarring } & 110 & 42.3 \\
\hline \multirow{6}{*}{$\begin{array}{l}\text { Symptoms prior to } \\
\text { diagnosis }\end{array}$} & Afebrile UTI & 106 & 40.7 \\
\hline & Febrile UTI & 61 & 23.5 \\
\hline & $\begin{array}{l}\text { Antenatal } \\
\text { hydronephrosis }\end{array}$ & 30 & 11.5 \\
\hline & Enuresis & 18 & 7 \\
\hline & Sibling VUR & 2 & 0.8 \\
\hline & Asymptomatic & 43 & 16.5 \\
\hline \multirow{8}{*}{$\begin{array}{l}\text { Urinary } \\
\text { comorbidities ( } n=59 \text {, } \\
22.7 \% \text { ) }\end{array}$} & $\begin{array}{l}\text { Duplicated } \\
\text { collecting } \\
\text { system }\end{array}$ & 20 & 7.7 \\
\hline & Nephrolithiasis & 13 & 5 \\
\hline & $\begin{array}{l}\text { Paraurethral } \\
\text { diverticulosis }\end{array}$ & 9 & 3.5 \\
\hline & $\begin{array}{l}\text { Horseshoe } \\
\text { kidney }\end{array}$ & 4 & 1.5 \\
\hline & Renal ectopia & 3 & 1.2 \\
\hline & Hypospadias & 3 & 1.2 \\
\hline & Renal agenesis & 3 & 1.2 \\
\hline & UPJ obstruction & 4 & 1.6 \\
\hline \multirow{3}{*}{ VUR outcome } & Persistent & 106 & 40.8 \\
\hline & Spontaneous & 49 & 18.9 \\
\hline & Surgical & 105 & 40.3 \\
\hline \multicolumn{2}{|c|}{$\begin{array}{l}\text { Patients with height } z \text {-score }<-2 \text { at } \\
\text { Diagnosis/Last visit }\end{array}$} & $4 / 5$ & $1.5 / 1.9$ \\
\hline \multicolumn{2}{|c|}{$\begin{array}{l}\text { Patients with Weight } z \text {-score }<-2 \text { at } \\
\text { Diagnosis/Last Visit }\end{array}$} & $5 / 3$ & $1.9 / 1.1$ \\
\hline \multicolumn{2}{|c|}{ Total number of patients } & 260 & 100 \\
\hline
\end{tabular}

VUR: Vesicoureteral reflux, UTI: Urinary tract infection, UP): Ureteropelvic junction patients according to the presence of UTIs during follow-up are shown in Table III.

\section{Discussion}

Primary VUR is an isolated abnormality, characterized by retrograde urine flow from the bladder. Whereas secondary VUR develops from an underlying urinary system anomaly such as neurogenic bladder, obstructive uropathy or posterior urethral valve (3). Treatment modalities are observational follow-up, continuous antibiotic prophylaxis and open or laparoscopic surgery (5). Controversy exists regarding the use of continuous antibiotic prophylaxis vs observation, but a recently published meta-analysis showed a significantly reduced risk of febrile and symptomatic UTIs with continuous antibiotic prophylaxis (6).

The best indicators of physical growth and development are weight and height gain in children. Growth monitoring according to standardized charts at regular intervals and early recognition of growth alteration are necessary for the well-being in children with chronic diseases.

In the literature, it was formerly suggested that VUR affects physical growth in children and also surgical treatment may lead to an improvement in growth parameters $(17,18)$. Wingen et al. (19) prospectively evaluated the growth in 236 children with VUR and found no relevance between renal scarring, VUR degree and laterality, UTI frequency and growth indices. Conversely, Polito et al. (20) recently reported that the initial height z-score was found to be significantly lower in children with bilateral VUR and renal scarring, and the same group showed the highest height z-score improvement at follow up (21). Although initial and final height z-scores were similar, our study showed significantly higher height z-score improvements in patients with renal scarring. This finding may be due to the effects of other clinical parameters on growth such as age at diagnosis, additional urinary malformations or UTIs. We speculate that patients with renal scarring had a better catch up in growth with optimal management.

Another study found that the patients who were diagnosed after their first month of life had higher height improvement than patients diagnosed before one month of age (22). We also investigated the age at diagnosis based on a cut-off value of 3 months. Weight and height z-scores at diagnosis and follow-up were found to be similar between those patients whose diagnosis was made before 3 months of age and those who were diagnosed after 3 months of age.

Moreover, two independent studies showed lower height z-score changes in patients with persistent VUR 
than surgical or spontaneous resolved VUR (7-9). In another recent study from our country, high-grade VUR was linked with growth alteration among 97 children. Additionally, bone age was found to be significantly lower in participants with renal scars compared to those without renal scars (23).

However, weight and height z-scores and their changes did not differ between those patients with persistent VUR, spontaneous resolution or surgical repair in our study. However, we found higher height z-score improvement in patients with a surgical procedure performed at least 6 months after the diagnosis. This data suggesting a better catch up in growth in children with delayed surgery, led us to think that it might be preferably to wait for spontaneous recovery for 6 months in selected cases.

UTI is the most relevant health problem in children with VUR. Malaki et al. (8) investigated growth parameters in children with UTIs and indicated that the presence, laterality and grade of VUR had no impact on growth parameters. Contrarily, striking evidence about the growthaltering effects of UTIs were present in our study. Final height and weight z-scores and weight z-score improvement were significantly lower in those patients with UTIs than those without UTIs at follow-up. This finding suggests that UTIs may cause growth retardation in patients with VUR.

Table II. Growth parameters and their changes at follow-up of patients with primary vesicoureteral reflux according to clinical characteristics

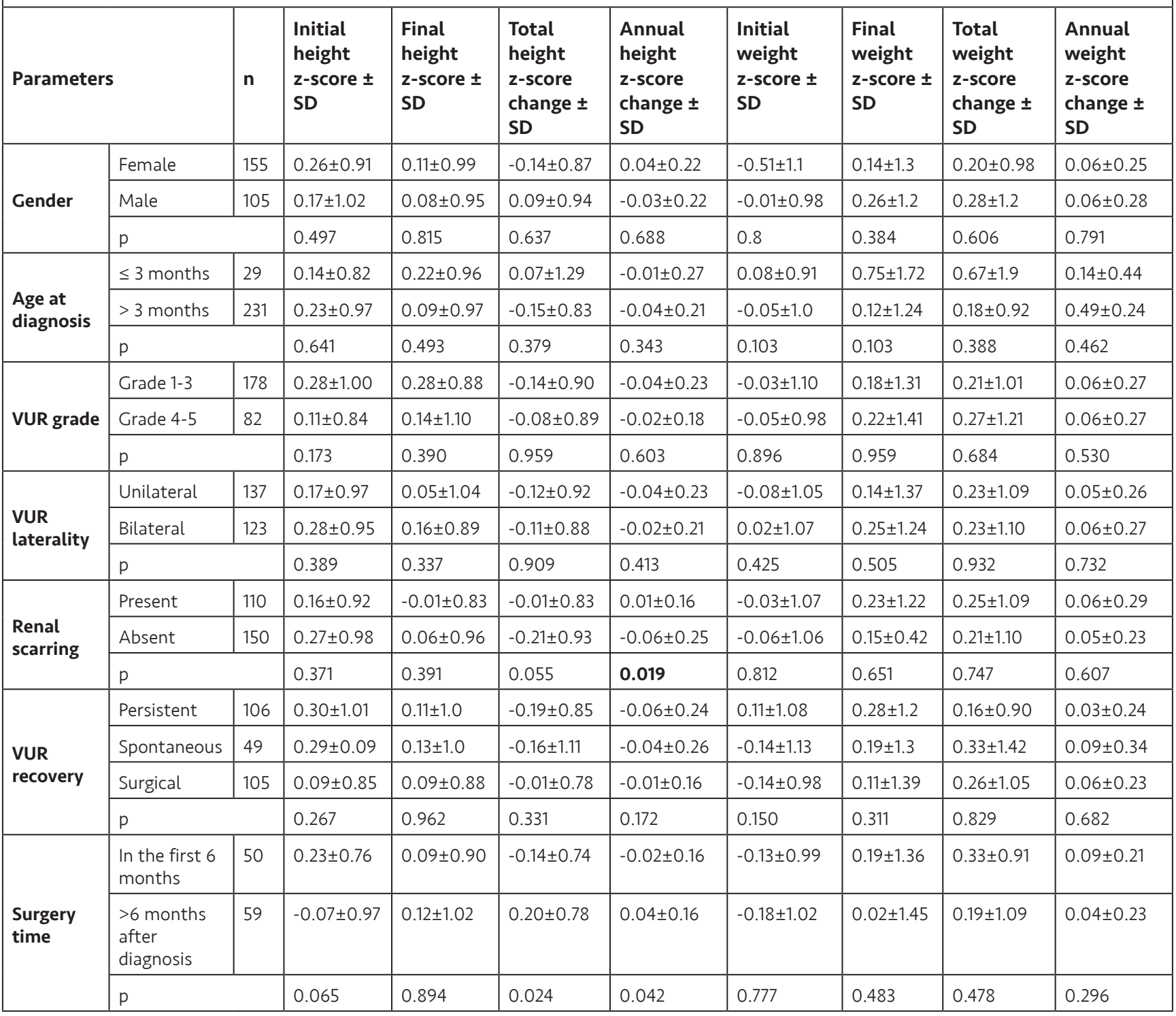

Significant $\mathrm{p}$ values are in bold

SD: Standard deviation, VUR: Vesicoureteral reflux 
Table III. Growth parameters of patients with primary vesicoureteral reflux according to presence of urinary tract infections at follow-up

\begin{tabular}{|c|c|c|c|c|c|c|c|c|c|}
\hline \multirow[b]{2}{*}{ Parameters } & \multicolumn{3}{|l|}{ UTI } & \multicolumn{3}{|c|}{ Febrile UTI at follow-up } & \multicolumn{3}{|c|}{ Afebrile UTI at follow-up } \\
\hline & $\begin{array}{l}\text { Yes } \\
(n=83)\end{array}$ & $\begin{array}{l}\text { No } \\
(n=177)\end{array}$ & p & $\begin{array}{l}\text { Yes } \\
(n=17)\end{array}$ & $\begin{array}{l}\text { No } \\
(n=243)\end{array}$ & $\mathbf{p}$ & $\begin{array}{l}\text { Yes } \\
(n=73)\end{array}$ & $\begin{array}{l}\text { No } \\
(n=187)\end{array}$ & p \\
\hline Initial height z-score \pm SD & $0.07 \pm 0.90$ & $0.30 \pm 0.98$ & $>0.05$ & $0.20 \pm 1.05$ & $0.23 \pm 0.95$ & $>0.05$ & $0.07 \pm 0.91$ & $0.29 \pm 0.97$ & $>0.05$ \\
\hline Final height z-score \pm SD & $-0.12 \pm 0.93$ & $0.21 \pm 0.98$ & 0.008 & $-0.31 \pm 0.96$ & $0.11 \pm 0.97$ & $>0.05$ & $-0.16 \pm 0.95$ & $0.20 \pm 0.97$ & 0.007 \\
\hline $\begin{array}{l}\text { Total height z-score change } \\
\pm \text { SD }\end{array}$ & $-0.05 \pm 0.20$ & $-0.02 \pm 0.23$ & $>0.05$ & $-0.23 \pm 0.68$ & $-0.11 \pm 0.91$ & $>0.05$ & $-0.23 \pm 0.90$ & $-0.08 \pm 0.90$ & $>0.05$ \\
\hline $\begin{array}{l}\text { Annual height z-score change } \\
\pm \text { SD }\end{array}$ & $-0.19 \pm 0.87$ & $-0.08 \pm 0.91$ & $>0.05$ & $-0.06 \pm 0.15$ & $-0.03 \pm 0.23$ & $>0.05$ & $-0.06 \pm 0.20$ & $-0.02 \pm 0.22$ & $>0.05$ \\
\hline Initial weight z-score \pm SD & $-0.22 \pm 0.97$ & $0.05 \pm 1.10$ & $>0.05$ & $-0.18 \pm 1.23$ & $-0.03 \pm 1.05$ & $>0.05$ & $-0.20 \pm 0.94$ & $0.03 \pm 1.10$ & $>0.05$ \\
\hline Final weight $z$-score \pm SD & $-0.20 \pm 1.07$ & $0.38 \pm 1.37$ & 0.001 & $-0.43 \pm 1.11$ & $0.24 \pm 1.30$ & 0.039 & $-0.12 \pm 1.10$ & $0.32 \pm 1.38$ & 0.035 \\
\hline $\begin{array}{l}\text { Total weight z-score change } \\
\pm \text { SD }\end{array}$ & $0.01 \pm 0.21$ & $0.08 \pm 0.28$ & 0.034 & $-0.43 \pm 1.10$ & $0.24 \pm 1.31$ & $>0.05$ & $0.09 \pm 0.92$ & $0.29 \pm 1.10$ & $>0.05$ \\
\hline $\begin{array}{l}\text { Annual weight z-score } \\
\text { change } \pm S D\end{array}$ & $0.02 \pm 0.92$ & $0.33 \pm 1.15$ & 0.031 & $-0.26 \pm 0.76$ & $0.26 \pm 1.12$ & $>0.05$ & $0.02 \pm 0.21$ & $0.07 \pm 0.29$ & $>0.05$ \\
\hline
\end{tabular}

UTI: Urinary tract infections, SD: Standard deviation

Significant $p$ values are in bold

Further analysis concerning UTIs showed that final height z-scores were significantly lower in patients with afebrile UTIs at follow up, while it was similar between patients with and without febrile UTIs. We thought this might be due to the small number of patients with febrile UTIs or the inadequate treatment of afebrile UTIs. Thus, we speculate that the symptoms of afebrile UTIs could be more often underestimated in clinical assessment.

\section{Study Limitations}

The limitations of our study were the absence of a prospective design and the lack of information about the nutrition status of participants.

\section{Conclusion}

Our study highlighted that the presence of renal scarring and UTIs at follow-up may lead to growth alterations in patients with primary VUR. We speculate that the presence of overall normal growth parameters may be due to a high antibiotic prophylaxis rate, which could prevent UTIs in our study group. The most striking insight in the present study was particularly the negative impact of afebrile UTIs on growth in patients with primary VUR. Therefore, physicians and parents should be aware of UTI symptoms even in the absence of fever in pediatric VUR.

\section{Ethics}

Ethics Committee Approval: The Ethics Committee of Dr. Behçet Uz Children's Training and Research
Hospital approved the study (approval number: B-10-4ISM-4-35-65-72, date: 27/09/2012).

Informed Consent: All patients and parents gave their informed consent prior to their inclusion in the study.

Peer-review: Externally peer-reviewed.

\section{Authorship Contributions}

Concept: R.M.K.E., E.S., Design: R.M.K.E., E.S., Data Collection or Processing: R.M.K.E., Analysis or Interpretation: R.M.K.E., E.S., Literature Search: R.M.K.E., Writing: R.M.K.E., E.S.

Conflict of Interest: None of the authors had conflict of interest.

Financial Disclosure: The authors declared that this study received no financial support.

\section{References}

1. Cooper CS. Diagnosis and management of vesicoureteral reflux in children. Nat Rev Urol 2009;6:481-9.

2. Peters C, Rushton HG. Vesicoureteral reflux associated renal damage: Congenital reflux nephropathy and acquired renal scarring. I Urol 2010;184:265-73.

3. Williams G, Fletcher JT, Alexander SI, Craig JC. Vesicoureteral reflux. I Am Soc Nephrol 2008;19:847-62.

4. Stefanidis C), Siomou E. Imaging strategies for vesicoureteral reflux diagnosis. Pediatr Nephrol 2007;22:937-47.

5. Elder IS, Peters CA, Arant BS Jr, et al. Pediatric vesicoureteral reflux guidelines panel summary report on the management of primary vesicoureteral reflux in children. J Urol 1997;157:184651. 
6. Wang $\mathrm{HH}$, Gbadegesin RA, Foreman JW, et al. Efficacy of antibiotic prophylaxis in children with vesicoureteral reflux: Systematic review and meta-analysis. J Urol 2015;193:963-9.

7. Menon P, Rao KL, Bhattacharya A, Mahajan JK, Samujh R. Primary vesicoureteral reflux: Progress of disease, somatic growth and renal parameters. Indian Pediatr 2004;41:1025-30.

8. Malaki M, Sayedzadeh SA, Shoaran M. Growth indices in urinary tract infection children with or without vesicoureteral reflux. Saudi J Kidney Dis Transpl 2011;22:723-6.

9. Fu LS, Hong YT, Shu SG. Height and weight growth in children with vesicoureteral reflux diagnosed before one year old. Urology 2009;74:1314-7.

10. Neyzi $O$, Günöz $H$, Furman $A$, et al. Türk çocuklarında vücut ağırlığı, boy uzunluğu, baş çevresi ve vücut kitle indeksi referans değerleri. Çocuk Sağlığı ve Hastalıkları Dergisi 2008;51:1-14.

11. (No authors listed). Medical versus surgical treatment of primary vesicoureteral reflux: Report of the International Reflux Study Committee. Pediatrics 1981;67:392-400.

12. Elder JS. Therapy for vesicoureteral reflux: Antibiotic prophylaxis, urotherapy, open surgery, endoscopic injection, or observation? Curr Urol Rep 2008;9:143-50.

13. Christian MT, McColl JH, MacKenzie JR, Beattie T). Risk assessment of renal cortical scarring with urinary tract infection by clinical features and ultrasonography. Arch Dis Child 2000;82:376-80

14. National Collaborating Centre for Women's and Children's Health (UK). Urinary Tract Infection in Children: Diagnosis, Treatment and Long-term Management. NICE Clinical Guidelines, No. 54 August 2007.
15. Krasinski KM. Urinary tract infections. In: Katz SL, Gershon AA, Flotez PJ (eds). Krugman's Infectious Diseases of Children. 10th ed. St Louis, Missouri, Mosby Year Book, 1998;606-19.

16. Chesney RW, Carpenter MA, Moxey-Mims M, et al. Randomized Intervention for Children with Vesicoureteral Reflux (RIVUR): Background commentary of RIVUR investigators. Pediatrics 2008;122:233-9

17. Merrell RW, Mowad IJ. Increased physical growth after successful antireflux operation. / Urol 1979;122:523-7.

18. Sutton R, Atwell JD. Physical growth velocity during conservative treatment and following subsequent surgical treatment for primary vesicoureteric reflux. Br J Urol 1989;63:245-50.

19. Wingen AM, Koskimies $O$, Olbing $H$, Seppänen I, TamminenMöbius T. Growth and weight gain in children with vesicoureteral reflux receiving medical versus surgical treatment: 10 -year results of a prospective, randomized study. International Reflux Study in Children (European Branch). Acta Paediatr 1999;88:5661.

20. Polito C, La Manna A, Capacchione A, Pullano F, lovene A, Del Gado R. Height and weight in children with vesicoureteric reflux and renal scarring. Pediatr Nephrol 1996;10:564-7.

21. Polito C, Marte A, Zamparelli M, Papale MR, Rocco CE, La Manna A. Catch-up growth in children with vesico-ureteric reflux. Pediatr Nephrol 1997;11:164-8.

22. Polito C, La Manna A, Mansi L, et al. Body growth in early diagnosed vesicoureteric reflux. Pediatr Nephrol 1999;13:876-9.

23. Keskinoğlu A, Darcan Ş, Keskinoğlu P, Kabasakal SC, Mir S. Growth evaluation in children with vesicoureteral reflux. Minerva Pediatr 2017;69:129-34. 